\title{
Crisis del Estado neoliberal y de la inserción internacional: evolución de las posiciones del gobierno de De la Rúa frente al ALCA entre agosto de 2000 y mayo de $2001^{1}$
}

\author{
Neoliberal State and international insertion crises: the evolution \\ of the positions of De la Rúa's administration around the FTAA \\ between August 2000 and May 2001
}

\section{Rodrigo Pascual $\left.\right|^{2}$, Igal Kejsefman ${ }^{3}$}

\begin{abstract}
Resumen: En el presente trabajo, nos proponemos mostrar que la ruptura de la subordinación de la Cancillería al Ministerio de Economía en torno a las negociaciones por el ALCA fue una de las manifestaciones de la crisis de la Convertibilidad -y por lo tanto de la inserción internacional que ella suponía- durante el gobierno de la Alianza. Asimismo, abordamos la crisis de la Convertibilidad como la crisis de las relaciones sociales que la sostenían y que se habían condensado en la forma de Estado neoliberal, excluyendo otras aristas de la misma. Desde esa perspectiva abordaremos los fundamentos que subyacían en las posiciones del Ministerio de Economía y la Cancillería entre agosto de 2000 a mayo de 2001, que primero asumieron la forma de una tensión latente (agosto del 2000 a marzo del 2001) y luego de una contraposición abierta (marzo a mayo del 2001).
\end{abstract}

Palabras clave: ALCA - Crisis del Estado Neoliberal - Inserción internacional - Cancillería Ministerio de Economía

\begin{abstract}
In this work we would like to show that the end of the subordination of the Ministry of Foreign Affairs to the Ministry of Economy around the negotiations for the FTAA was one of the manifestations of the Convertibility crisis - and, as a result, of the international insertion that this entailed - during the Alianza's government. Moreover, we look at the Convertibility crisis as the crisis of the social relations which supported it and which had been condensed in the form of a Neoliberal state, excluding all other elements. From this perspective, we will analyze the basic principles underlying the positions of the Ministry of Economy and the Ministry of Foreign Affairs between August 2000 and May 2001, which first acquired the shape of a latent tension (from August 2000 to March 2001) and afterwards turned into open opposition (from March to May 2001).
\end{abstract}

Keywords: FTAA - Crisis of the neoliberal State - International insertion - Ministry of Foreign Affairs - Ministry of Economy

\footnotetext{
${ }^{1}$ Recibido: 26/12/2017. Aceptado: 10/05/2018

${ }^{2}$ Docente Investigador del Instituto de Cultura, Sociedad y Estado de la Universidad Nacional de Tierra del Fuego. Becario Posdoctoral CONICET. Licenciado en Ciencia Política (UBA). Doctor en Ciencias Sociales (UBA). Investigador UNQ.rpascual@untdf.edu.ar.

${ }^{3}$ Economista (UBA), Mg. en Estudios Sociales Latinoamericanos (UBA), Becario doctoral CONICET con lugar de trabajo en el Instituto de Estudios de América Latina y el Caribe (IEALC-FSOC-UBA). igalkej@gmail.com
} 


\section{Objetivos y estructura del trabajo.}

En el presente trabajo, nos proponemos mostrar que la ruptura de la subordinación de la Cancillería al Ministerio de Economía en torno a las negociaciones por el ALCA fue una de las manifestaciones de la crisis de la Convertibilidad -y por lo tanto de la inserción internacional que ella suponía- durante el gobierno de la Alianza. Asimismo, abordamos la crisis de la Convertibilidad como la crisis de las relaciones sociales que la sostenían y que se habían condensado en la forma de Estado neoliberal, excluyendo otras aristas de la misma. Algunas de ellas son traídas a colación sólo en la medida en que resultan ineludibles para alcanzar el objetivo del presente artículo.

Antes de centrarnos en los vaivenes de la política exterior argentina entre agosto del 2000 y mayo del 2001, dedicaremos una primera sección del trabajo a exponer el vínculo entre la forma de Estado y la política exterior, en general, y el vínculo entre el ALCA y la subordinación de los trabajadores en particular.

En un segundo apartado, nos centraremos en los debates en torno al Plan Real en Brasil que llevaron a su crisis y replanteo a partir de la devaluación de 1999. Este punto reviste una importancia fundamental dado que la crisis brasileña aceleró la crisis de la Convertibilidad y porque la posición asumida por Cardoso a partir de dicho año en torno al ALCA gravitó fuertemente en el debate argentino sobre el Tratado continental.

En el tercer y cuarto apartado, nos dedicaremos exclusivamente a los fundamentos que subyacían en las posiciones del Ministerio de Economía y la Cancillería durante el período abordado en el trabajo, que primero asumieron la forma de una tensión latente (agosto del 2000 a marzo del 2001) y luego de una contraposición abierta (marzo a mayo del 2001). Expondremos allí que el acercamiento de Cancillería a la posición de Brasil, sobre el ALCA, implicó un proceso de incipiente politización de la política exterior que cuestionaba, de modo mediato, la forma de subordinación de los trabajadores cristalizado en la Convertibilidad. Por el contrario, la posición del Ministerio de Economía que buscó negociar bilateralmente el acuerdo de libre comercio a cambio de ayuda financiera, implicaba sostener los mecanismos despolitizados y exogeneizados que se condensaban en la Convertibilidad. En los dos últimos apartados mostraremos que el desarrollo de los debates entre ambas carteras puso de manifiesto la creciente resistencia de los trabajadores, organizaciones sociales, civiles y partidos de izquierda, así como altermundistas, estudiantes y sectores de la pequeña burguesía a los ajustes deflacionarios que suponía la inserción sin mediaciones al mercado mundial.

\section{La política exterior del Estado neoliberal: el ALCA y la subordina- ción de los trabajadores.}

Desde la perspectiva aquí desarrollada, comprendemos al Estado como una de las formas que asumen las relaciones sociales. Más específicamente, como el modo de existencia de relaciones de dominación política en el capitalismo; entendiendo a este como resultante de la separación histórica de los productores de los medios de producción (Hirsch, [1977] 2017). El Estado es una relación social que supone y reproduce aquella separación histórica, sobre la cual se funda un proceso de separación aparente-real (Holloway y Picciotto, 1994) entre una esfera de la dominación política respecto de la 
esfera de la producción/explotación económica. En última instancia el éxito de la dominación política queda supeditado a la capacidad del Estado de mostrarse como un tercero neutral que se erige sobre (con independencia de) las relaciones antagónicas entre capitalistas y trabajadores propias de la esfera productiva (Holloway y Picciotto, 1994). El Estado, como modo de dominación del capital sobre el trabajo, asume formas de Estado específicas en cada momento histórico. En la forma de Estado, entonces, se materializan relaciones de fuerza entre las clases y al interior de las fracciones de la burguesía (Poulantzas, 1986). Esta materialización se manifiesta en los aparatos de Estado y en la relación entre ellos y entre sus secciones. Asimismo, conlleva un modo específico de inserción internacional política y económica. Las correlaciones de fuerza entre esos aparatos y secciones, y del modo de inserción internacional, expresan relaciones de fuerza entre capitalistas y trabajadores.

La forma de Estado, que se correspondió con el período de negociaciones por el ALCA que analizaremos aquí (2000 - 2001), se conformó entre 1989-1991 ${ }^{4}$ (Piva, 2012). En ese lapso se terminó de consumar un modo de subordinación del trabajo que expresaba relaciones de fuerza favorables para el gran capital, con capacidad de insertarse competitivamente en el mercado mundial, y del capital financiero. Estas fracciones fueron las que impulsaron la modernización neoliberal, que terminó de estructurarse alrededor del Plan de Convertibilidad y las trasformaciones que consumaron la incorporación sin mediaciones de la economía argentina al mercado mundial. De esta manera, se produjo una subordinación política y económica del trabajo al funcionamiento pleno de la acción de la ley del valor a escala mundial, así como a los flujos y reflujos de capital dinero. Esto tuvo expresión en las transformaciones operadas en la política exterior orientada a reducir las relaciones exteriores a las necesidades de la acumulación, y en este sentido, despolitizándolas.

La forma de Estado neoliberal -expresada en el Plan de Convertibilidad- supuso la restricción de la autoridad del Banco Central para emitir moneda -sujetando dicha función a los flujos y reflujos de divisas-, la completa liberalización comercial -desarmando los mecanismos regulatorios-, y la exogeneización de funciones soberanas a tribunales externos en potenciales litigios con capitales foráneos -mediante la firma de 54 tratados bilaterales de inversiones durante la década del noventa-. En el corazón del Tratado del ALCA que el Estado Argentino pretendió negociar estaba ubicado en el capítulos sobre inversiones (Arceo, 2002; Estay y Sánchez, 2005), el cual proponía - entre las cuestiones más destacables - la sujeción de todos los Estados a tribunales internacionales en caso que se produjeran diferencias entre los inversores (extranjeros) y los Estados receptores como medio de garantizar la ganancia de las empresas ante casi cualquier eventualidad (Pascual, Ghiotto y Lecumberri, 2007; Pascual y Ghiotto, 2008; Ghiotto, 2013; Pascual, 2016). De esta manera, el Estado puso fuera de sí algunos mecanismos específicos que suponen el comando social (soberanía), en general, y de la inserción internacional de la economía argentina en el mercado mundial, en particular. En conclusión, la forma de Estado neoliberal constituyó mecanismos despolitizados y exogeneizados.

La liberalización conjunta del comercio exterior y de las finanzas expuso la debilidad y el atraso productivo de la economía argentina a la competencia de los capitales más productivos del mundo. En este escenario, los capitalistas que operaban localmente

\footnotetext{
${ }^{4}$ Al tiempo que sus raíces más profundas se remontan a las transformaciones iniciadas en 1975/6.
} 
debían aumentar la productividad de los trabajadores, principalmente, incorporando tecnología (sustituyendo trabajo por capital). Con dicho fin los capitales debían subordinar exitosa y duraderamente a los trabajadores, so pena de sucumbir frente a las importaciones. La capacidad de las empresas de insertarse exitosamente en el mercado mundial dependió, en general, de su asociación con empresas líderes en la esfera internacional constituyendo una alianza entre ambas fracciones. El vínculo con Estados Unidos y las políticas de contención de Bush (h) -desde la caída de la Unión Soviética- y de Clinton durante la crisis del Tequila- facilitaron el acceso a las divisas que requería el Plan de Convertibilidad y que permitieron la transformación productiva -y no una simple desindustrialización- de la Argentina durante los noventa (Piva, 2012 y Grigera, 2011). Bajo este escenario, los organismos financieros internacionales jugaron un papel central. En efecto, "el FMI, condicionando sus préstamos a la desregulación y flexibilización de los mercados locales, como se realizó, impuso una nueva relación entre el capital y el trabajo en los diferentes países y, en dicho proceso, transformó profundamente los mercados de trabajo locales y las relaciones de fuerza entre las clases" ${ }^{5}$ (Robinson, 2009, p.36). De esta forma se consagró y profundizó la debilidad de los trabajadores.

Así como las correlaciones de fuerza entre clases y fracciones de clase cristalizaron en la forma de Estado neoliberal y el modo específico de subordinar el trabajo, ésta también se puso de manifiesto en la composición del gabinete nacional y las relaciones de fuerza al interior del poder ejecutivo. El poder del Ministerio de Economía por sobre el resto del gabinete, y su convalidación por medio del Presidente, cristalizaba el modo de subordinación despolitizado y exogeneizante. El poder del Ministerio de Economía, en efecto, emanaba del éxito de la Convertibilidad y de las correlaciones de fuerza entre las clases que ella condensaba. Su poder dependía del éxito de la sujeción de la política monetaria a los movimientos del capital global.

Dentro de este esquema, la política exterior estableció como objetivos principales la búsqueda de nuevos mercados y la ampliación de los tradicionales. Estos motivaron una despolitización en la política exterior que se adecuó y subordinó a las necesidades trazadas por el Ministerio de Economía y a las transformaciones impulsadas por la gran burguesía exportadora, condensadas en las reformas modernizadoras.

La Cancillería, entonces, acompañó los cambios con acciones que tendieron a lograr la inserción sin mediaciones de la economía argentina en el mercado mundial. En ese sentido, pueden indicarse a: la firma de acuerdos comerciales, el ingreso al CIADI en 1991, el acuerdo del MERCOSUR también de 1991 y la promoción de Tratados Bilaterales de Inversiones mencionados anteriormente. Asimismo, esta despolitización representó una continuidad con la política exterior iniciada por Domingo Cavallo que, como canciller, efectivizó la salida del grupo de Países No Alineados, la desmilitarización y la desmalvinización (Corigliano, 2000a; Míguez, 2012). Conjuntamente, esta reorientación de la política exterior supuso una mayor integración en el mercado mundial y al sistema internacional de Estados (Corigliano, 2000b).

Sintéticamente, bajo la forma de Estado neoliberal la Cancillería se subordinó a las necesidades trazadas por la Convertibilidad sujetándose, por este medio, a la conducción

\footnotetext{
5 "The IMF, by conditioning its lending on a deregulation and flexibilization of local markets, as it has often done, is imposing the new capital-labor relation on the particular country and, in the process, fundamentally transforming local labor markets and class and power relations"
} 
del Ministerio de Economía. El rol protagónico de Economía en las negociaciones comerciales internacionales, contemplado en los ámbitos bi y multilaterales, manifestó de modo específico esa subordinación. Sin embargo, la política exterior no estuvo inmediatamente subordinada a ese Ministerio, sino que la Presidencia también jugó un rol central en la conducción de la Cancillería (Bologna, 1998, y Busso, 1994). Cabe destacar, sin embargo, que el protagonismo del Presidente de la Nación en la política exterior -como en el resto del gabinete nacional- apuntaba a convalidar las políticas impulsadas por el ministerio de Economía (Piva, 2012; Bonnet, 2008; Pascual, 2016).

Sin embargo, desde 1998 comenzó a desenvolverse con intensidad creciente una resistencia a los modos de subordinación de trabajo inscriptos en la convertibilidad, lo que conducía a la crisis al conjunto de la economía. Con este trasfondo sostenemos que el enfrentamiento entre el ministerio de Economía y la Cancillería durante los años 2000 y 2001 en torno a las negociaciones por el ALCA manifiestan dicha crisis. En este sentido, buscaremos exponer a lo largo del trabajo que la política de la Cancillería, en vistas a un ALCA políticamente viable, puede comprenderse a la luz de dicha crisis y que, en ese marco, fue su viabilidad política la que la acercó a la posición expresada por el Estado brasileño. La convergencia política con Brasil en torno a forma concreta que asumiría una futura integración continental, aparecía como la orientación políticamente viable para sortear la crisis y profundizar la reestructuración productiva iniciada a principio de la década de los noventa.

\section{Crisis y replanteo del Plan Real en Brasil y sus impactos en Argentina}

Para abordar de forma más acabada las tensiones en el sostenimiento del Plan de Convertibilidad y las pujas entre los Ministerios por definir sus rumbos y alternativas durante el año 2000 debemos remontarnos a los acontecimientos que definieron la devaluación y reconfiguración del Plan Real de Brasil en 1999.

Las políticas neoliberales, habían implicado en Brasil un tipo de inserción internacional que, según Lafer, diluyeron lo externo respecto de lo interno. "Esta dilución fue un dato de la realidad que terminó imponiendo una pausa para pensar de qué manera hacer viable, en las condiciones actuales, el desarrollo del espacio nacional" (Lafer, [2001] 2002, p.132). La desagregación de las cadenas productivas a escala planetaria había hecho del outsourcing una práctica empresaria habitual. "Por esta razón la inserción en la economía mundial gestionada por el Estado [brasileño], viable por la escala continental del país y operado según la lógica anterior del nacionalismo de fines, se volvió inoperante" (Lafer, [2001] 2002, p. 138).

Desde Collor de Melo y fundamentalmente a partir de la presidencia de Cardoso, Itamaraty se propuso participar de la formulación del nuevo tablero mundial que se estaba configurando, como el mejor modo de garantizar los intereses nacionales (Lafer, [2001] 2002, p. 144). En ese marco, Brasil renunció a su histórica posición en la que se reservaba la soberanía nuclear, incorporándose en 1998 al Tratado de No Proliferación Nuclear impulsado por Estados Unidos. De este modo Brasil se acercaba a la primera potencia mundial y, al mismo tiempo, apuntaba a intervenir en la elaboración de una agenda global. En efecto, Lafer ([2001] 2002) sostenía que el tiempo económico, de plazos cada vez más cortos, planteaba como desafío a la sincronía con los tiempos políticos 
para llevar adelante los cambios necesarios en función de la inserción comercial eficaz que permitiera el desarrollo nacional. Desde su punto de vista, la respuesta a tal desafío debía ser la diplomacia de las negociaciones comerciales de la OMC, el ALCA y el Mercosur que permitiera "la elaboración de reglamentación (...) que Brasil necesita para asegurar un espacio -que se está reduciendo- para la conducción de sus ${ }^{6}$ políticas públicas" (Lafer, [2001] 2002, p. 148).

"El consenso del conjunto de la clase dominante brasileña en torno a las reformas neoliberales eclipsó -aunque no disipó- las diferentes posiciones sobre el grado y profundidad en que debía aplicarse el programa neoliberal" (Berringer, 2015 p.116). En 1996, por ejemplo, se conformó la Coalición Empresarial Brasileña (CEB) cuyo objetivo radicaba en la defensa de sectores industriales en el marco de las negociaciones del ALCA. Ese mismo año sucedieron, además, protestas de la Federación de Industrias del Estado de San Pablo (FIESP) y la Confederación Nacional de la Industria (CNI). El evidente beneficio de la transformación productiva tenía como contraparte crecientes tensiones al interior de la burguesía (Berringer, 2015, p. 96). La FIESP impulsó en 1997 el Foro de las Reformas con el fin de discutir, entre otros elementos, el modo subordinado por el cual Brasil se insertaba en el mundo. La candidatura única y elección de Horacio Lafer Piva al frente de la FIESP y el Centro de Industrias del Estado de San Pablo (CIESP) dio cuenta del nivel de acuerdo que había entre los industriales en torno a la continuidad neoliberal y a la necesidad de reformas.

Simultáneamente, se desplegaron una serie de protestas por parte de organizaciones sociales y políticas brasileñas. La Central Única de los Trabajadores (CUT) y un lento, aunque sostenido, ascenso del Partido de los Trabajadores (PT) pusieron de manifiesto un creciente cuestionamiento a la orientación exportadora de la economía que relegaba el mercado interno (Berringer, 2015). El reclamo de estos sectores sociales, en torno a la inserción internacional, convergía con las posiciones de sectores burgueses mercadointernistas. No obstante, a pesar de su vulnerabilidad y las controversias, la continuidad del Plan Real estuvo garantizada por un préstamo otorgado por el FMI a Brasil durante 1998.

Ciertamente, la intensidad de las demandas planteadas por las organizaciones sociales y políticas de los trabajadores no arribaron al punto de abrir un enfrentamiento al interior de la burguesía que impidiera que las diferentes fracciones confluyeran en un nuevo acuerdo en torno a la inserción internacional. A pesar de la creciente dificultad de Estados Unidos para responder a las necesidades de liquidez de la periferia en crisis, y de las presiones de sectores de la burguesía que cuestionaban la estabilización macroeconómica como el único objetivo de la política económica (Diniz, 2010), las diversas fracciones capitalistas llegaron a un nuevo acuerdo en torno a la inserción internacional y el rol del mercado interno, sin mediar una crisis política (Martuscelli, 2015). El nuevo equilibrio entre las fracciones burguesas motivó la devaluación del primero de enero de 1999 y un plan de ajuste con fuerte impacto negativo sobre los trabajadores: el salario mínimo cayó en un 30\%, mientras que el salario real medio lo hizo en un 5,5\%, junto a un aumento del trabajo informal. En este sentido la crisis y transformación del Plan Real emergieron como el producto de las luchas por la inserción internacional y sus implicancias en el conflicto distributivo, el capital financiero y las empresas extranjeras que operaban localmente fueron las más desfavorecidas.

\footnotetext{
${ }^{6}$ Destacado de los autores.
} 
Con la devaluación, en cierta forma, se producía relativo desacople entre lo externo y lo interno. Esto se expresó en una mayor participación e injerencia de los diversos sectores empresarios en las negociaciones por el ALCA. De esta manera, el Estado brasileño se politizaba en la medida en que operaba como mediador de las presiones externas e internas, negociando con cada uno de los sectores afectados por el Tratado. Desde nuestro punto de vista, la crisis y replanteo del Plan Real -que en definitiva representó la crisis y replanteo de la inserción internacional de Brasil- tuvo implicancias en la posición de la Cancillería argentina.

La crisis del Real y la devaluación abrieron un cuadro de fricciones en la burguesía argentina en torno a la Convertibilidad. Ello se manifestó en el quiebre del Grupo de los Ocho, abriendo el camino para que "varias fracciones de la burguesía repensaran su inserción regional, tanto en el marco del MERCOSUR -especialmente en relación a su principal socio, Brasil- como así también su futuro lugar en instancias mayores de integración como el ALCA (Área de Libre Comercio de las Américas)" (Kan, 2009: 1). La conformación del Grupo Productivo, que inicialmente buscaba mejorar la competitividad sin modificar el tipo de cambio nominal -es decir, sin cambiar el vínculo con el mercado mundial-, esbozaba diferencias en torno al futuro de la Convertibilidad. Estos sectores promovían un modelo de desarrollo capitalista en "base a exportaciones, que, dado el tipo de perfil productivo predominante, sólo resulta[ba] viable con un mayor deterioro de la participación de los trabajadores y de las PyMEs en el ingreso total generado en el ámbito industrial" (Schorr, 2001, p. 7).

En 1999, también comenzaron a tensarse la relación al interior de la UIA (Unión Industrial Argentina). Esto se produjo, principalmente, entre los grandes industriales competitivos internacionalmente -nucleados en el Movimiento Industrial Argentino- y los capitales menos competitivos o productores de bienes transables -nucleados en el Movimiento Industrial Nacional-; no obstante, mantuvieron la alternancia pactada en 1993. Estos dos núcleos de la central empresaria "si bien coinciden en sus aspectos centrales, presentan ciertas diferencias de significación que vale la pena mencionar: uno se encuentra más ligado a las oportunidades que ofrece el mercado ampliado del Mercosur, y el otro está más vinculado con la integración de la Argentina al Área de Libre Comercio de las Américas (ALCA)" (Schorr, 2001, p. 9).

En síntesis, la devaluación brasileña provocó movimientos internos en las diversas fracciones de la burguesía argentina en torno a la inserción internacional dado que el creciente descontento social impedía efectuar una deflación real (bajas salariales) que permita competir internacionalmente con un tipo de cambio nominal fijo. Aquel descontento social, expresado a través de fricciones entre fracciones capitalistas, se cristalizó al interior del gobierno argentino y esto se puso de manifiesto en las negociaciones por el ALCA.

\section{Tensiones latentes entre Economía y Cancillería: julio del 2000 - marzo 2001}

Hasta julio de 2000, las posiciones del Ministerio de Economía y la Cancillería en torno a las negociaciones por el ALCA fueron consonantes. Ambos consideraban que al Tratado debía negociarse desde el MERCOSUR y junto a Brasil. Pero la necesidad de conseguir financiamiento para sostener la Convertibilidad, la falta de ayuda externa por 
parte de Europa y las diversas presiones de Estados Unidos y Brasil, así como el anuncio de la inminente firma de un tratado de libre comercio entre Estados Unidos y Chile, tensó al gabinete nacional. En este contexto el ministro de Economía Machinea se alejó de la posición equidistante que la Cancillería pretendía sostener entre Europa y Estados Unidos. El ministro de Economía entendía que acercarse a Estados Unidos iba a permitir garantizar una próxima ayuda financiera ${ }^{7}$.

El alejamiento de Economía de la posición de la Cancillería no sólo implicaba un distanciamiento de Europa, sino también de Brasil. Al finalizar el año 2000 la inclinación por Estados Unidos ya era manifiesta. Consideramos que ponerse bajo la protección de Estados Unidos tenía por objeto garantizar ayuda financiera que permitiera reproducir la Convertibilidad, es decir, reproducir la subordinación de los trabajadores bajo mecanismos exogeneizantes y despolitizados.

En diciembre de 2000, ante la inminencia del default, Argentina negoció un salvataje financiero con el FMI facilitado por el apoyo de Estados Unidos que, a pesar de no haber estado dispuesto a prestar dinero, actuó a favor del acuerdo ${ }^{8}$. A cambio, en enero Estados Unidos reclamó que Argentina lo acompañara en el impulso del ALCA (Pascual, 2016). De esta manera, las negociaciones del salvataje parecían consolidar la posición sostenida por la cartera económica de usar al ALCA como moneda de cambio para acceder a los empréstitos necesarios. Pocos días antes del anuncio del desembolso financiero denominado Blindaje ${ }^{9}$, comenzaron los desencuentros. Por un lado, se encontraban los sectores que se hallaban en sintonía con la propuesta norteamericana pro-ALCA que pretendía un acuerdo negociado de modo atomizado entre Estados. Por el otro, se encontraban quienes pretendían coludir junto a Brasil para negociar y de esa manera moderar el alcance del Tratado $^{10}$. El salvataje en diciembre de 2000 parecía confirmar la victoria de los primeros.

El Canciller era más cauto. Durante diciembre de 2000 argumentaba que era imposible adelantar las negociaciones por el ALCA, como proponía Estados Unidos. Entendía que el gobierno de Bill Clinton se encontraba en retirada y que, ante la iniciativa de la Unión Europea de integrar a los países del Este, América del Sur iba a ser prioridad para Estados Unidos ${ }^{11}$. De manera que, según la mirada de la cancillería, no tenía sentido acelerar los plazos. El Canciller Rodríguez Giavarini sostenía que convenía mantener una posición conjunta con Brasil limitando el alcance del acuerdo. Su posición tenía como consecuencia reducir los efectos de la reestructuración dado el bloqueo a políticas defla-

\footnotetext{
${ }^{7}$ La Nación, 03/08/00.

${ }^{8}$ Clarín, 18/12/00. También puede revisarse La integración desde arriba (Kan, 2015).

${ }^{9}$ Se denominó Blindaje en tanto buscaba blindar la economía del default

${ }^{10}$ Un vocero del gobierno anunciaba que “Argentina le pedirá a Estados Unidos un esfuerzo por adelantar el lanzamiento del ALCA (el proyecto de integración de toda América) para mediados o fines de 2003, dos años antes del plazo que establecieron los Presidentes". Al mismo tiempo, diversas fuentes diplomáticas ratificaban que "La Argentina quiere llegar al ALCA de la mejor forma posible y al lado de su socio en el MERCOSUR, Brasil" La Nación, 05/12/00.

11 “En rigor, a Rodríguez Giavarini le gusta separar la ansiedad de la política: cree que, si como lo anunció Javier Solana en Buenos Aires, Europa privilegiará por ahora la integración de los países del Este, América Latina terminará siendo una región invalorable para los Estados Unidos. "¿Para qué apurarse entonces?", dicen que pregunta." en La Nación, 03/08/00.
} 
cionarias. Las divergencias ponían de manifiesto las dificultades para el sostenimiento de la Convertibilidad y eran indicativas de la dificultad de la prolongación temporal de los mecanismos de subordinación del trabajo implícitos en ella.

Durante los meses de enero y marzo, el Canciller y el Ministro de Economía protagonizaron un intenso juego de presiones sobre la posición definitiva que Argentina tendría frente al ALCA. Asimismo, durante esos meses se intensificó la crisis económica, siendo cada vez más urgente la necesidad de obtener más ayuda financiera para mantener el esquema convertible. Esta situación resultó en una tregua que duró hasta la renuncia de Machinea en marzo de 2001. En esos días pudo observarse que las posiciones sobre el ALCA corrían junto a los dilemas la Convertibilidad, aunque las tensiones permanecieron latentes y no llegaron a un enfrentamiento público.

En enero de 2001, Estados Unidos renovó su estrategia para relanzar el ALCA y buscó adelantar dos años su lanzamiento, programado originalmente para 2005. Las declaraciones de los futuros funcionarios del gobierno republicano de Bush (h), apuntaban a sortear los obstáculos externos (Brasil) e internos (los sindicatos, los ambientalistas, los empresarios agroindustriales) que entorpecían el avance de las negociaciones. A fines de enero de 2001, Robert Zoellick (representante comercial norteamericano) aseguraba que su gobierno iba a pedir el Fast Track al Congreso. Su idea era garantizar, o al menos encaminar, las negociaciones para abril, momento en que se realizaría la III Cumbre de las Américas en Quebec. El objetivo era presionar a Brasil y así avanzar en las negociaciones por el ALCA ${ }^{12}$. El Fast Track era fundamental y los primeros cien días de gobierno eran claves para su concreción.

Al comienzo de enero, el gabinete del Ejecutivo argentino mantuvo una posición relativamente unificada. Los negociadores norteamericanos estaban atentos de la situación de Argentina, sabían que las necesidades financieras iban a ser su principal carta de negociación. Asimismo, conocían las rispideces que atravesaban las relaciones bilaterales entre Argentina y Brasil: por un lado, la devaluación del Real había generado fuertes tensiones entre los países (Kan, 2009); por el otro, Brasil era el principal socio comercial de Argentina. Por ello los funcionarios del gobierno de Bush (h) comprendían que el MERCOSUR iba a ser su principal escollo. En ese contexto, a mediados de enero de 2001, Zoellick presionó a Argentina para que apoyara su iniciativa ${ }^{13}$.

Esta coyuntura colocó a Argentina en una posición de pívot (Miranda, 2001) de la cual el gobierno nacional intentó sacar provecho. En ese momento los funcionarios argentinos se declaraban favorables al adelantamiento del ALCA y también respecto de la posición de Brasil de negociar los contenidos del Tratado de conjunto. Pero esa posición dual exponía las tensiones internas entre las dos posiciones existentes entre los funcionarios, y que esa posición era producto de la debilidad de Argentina. En este contexto, la Cancillería anunció que demandaría a Estados Unidos la total liberalización del comercio y anunció que llevaría esa propuesta a los encuentros continentales de abril de 2001, a realizarse en Buenos Aires y Quebec. Sin embargo, las expectativas eran bajas ya que difícilmente Estados Unidos aceptaría esta clase de pedidos.

\footnotetext{
${ }^{12}$ La Nación, 31/01/01.

${ }^{13}$ Clarín, 12/01/01.
} 
El Canciller informó a Condoleezza Rice y Colin Powell que acordaba con la posición de Estados Unidos de adelantar los tiempos del Tratado, aunque manifestó que prefería el año 2004 en lugar de 2003. Pero esto no era una propuesta aceptable para Estados Unidos, pues estaría muy próximo a las elecciones presidenciales y haría poco viable su aprobación en un Congreso que recibía intensas oposiciones al Tratado. Sin embargo, cabe destacar que más allá de las discrepancias, la posición de Argentina era proclive a que se negociara el ALCA e incluso que se adelantaran las fechas de inicio ${ }^{14}$. Argentina quedaba en la disyuntiva de negociar con los Estados Unidos de forma bilateral o desde el MERCOSUR bajo la égida de Brasil. La primera opción la distanciaba de su principal socio comercial $^{15}$; la segunda excluía la negociación directa y lo llevaba a un resquebrajamiento de las relaciones con Estados Unidos. La debilidad de la posición de pivot era notoria.

Días después de darse a conocer esta noticia, Giavarini dio a entender que iba negociar el ALCA bajo la inamovible condición de que Estados Unidos libere el comercio del sector agrícola, postura que lo acercó a las posiciones de Itamaraty. El canciller no pretendía boicotear el ALCA sino que simplemente perseguía un pragmatismo comercialista: sin apertura del sector agrícola no habría Tratado. Pero ese mismo pragmatismo lo enfrentaba con Economía. Desde el punto de vista de la Cancillería subordinarse a las necesidades norteamericanas para obtener ventajas comerciales y/o financieras parecía poco útil teniendo en cuenta la brecha de productividad entre ambas economías. Negociar sin condicionamientos a cambio de las posibles ofrendas financieras representaba para el Canciller una ingenuidad. En este sentido, Giavarini solía preguntar retóricamente por los beneficios que esa subordinación había traído durante los dos mandatos de Carlos Menem ${ }^{16}$.

El 9 de febrero, el gobierno argentino recibió la visita del nuevo Ministro de Relaciones Exteriores de Brasil, Celso Lafer, quien aclaró que el MERCOSUR era la prioridad de su país. Lafer jugó su principal carta frente a Giavarini: el superávit comercial que el comercio bilateral dejaba a Argentina. Lafer declaró que para Brasil no era prioridad la discusión de los tiempos sino del contenido del Tratado, cuestionó la posibilidad de firmarlo en 2005 y se manifestó a favor de dilatarlo el máximo tiempo posible.

Las declaraciones de Lafer, introdujeron más tensiones en el gobierno argentino. Era sabido que el ministro de Economía abogaba por una posición pro-norteamericana y que Giavarini oscilaba entre acompañar a Brasil y apoyar en algunas cuestiones a Estados Unidos. Sin embargo, el Canciller era más pragmático: mientras que Brasil aportaba ingresos genuinos, Estados Unidos sólo ofrecía una potencial ayuda financiera ${ }^{17}$. El reclamo

\footnotetext{
${ }^{14}$ A diferencia de Brasil, socio principal en el Mercosur, la Argentina no se opone a adelantar el calendario del ALCA, como quieren los Estados Unidos, y tampoco tiene una postura reticente ante el Plan Colombia, otro punto cantado para la agenda de los cancilleres. La Nación, 04/02/01.

${ }^{15}$ La Nación, 31/01/01, 04/02/01.

16 "Todo lo que la Argentina ofreció en materia de previsibilidad a los ojos de los Estados Unidos durante el decenio de Menem se tradujo en honores como la designación de aliado extra OTAN. Pero no ha tenido ningún correlato en materia de comercio". Clarín, 21/01/01, destacado en el original

17 "Según cifras oficiales de comercio exterior, del aumento de las exportaciones entre 1992-2000 el Mercosur aportó el $\mathbf{4 3 , 2 \%}$ y la Unión Europea sólo el 5,8\%. Las mismas estadísticas indican que el 61,2\% de las ventas nacionales tienen como destino el mercado de países americanos, contra el 7,5\% de Europa. En el caso de las manufacturas de origen industrial, el aporte del Mercosur trepa al 59,6\% contra el 10,9\% del resto de América y el 8,7\% de la Unión Europea. En todos esos guarismos sobresale un dato: Brasil
} 
de Lafer fue unívoco: Argentina debía negociar junto a Brasil para obtener un mejor acuerdo dejando a un lado la cuestión de los plazos.

La decisión final de Giavarini se sentenció luego de una reunión que sostuvo con Lafer. Después de aquel encuentro la Cancillería asumió que la mejor alternativa era negociar junto con el país vecino privilegiando el tratamiento de los temas por sobre los tiempos. El superávit comercial con Brasil y los requerimientos de divisas se impusieron sobre cualquier otra cuestión. Ingresar al ALCA sin condicionamientos, en ese contexto, sólo profundizaría los efectos negativos de la Convertibilidad, lo que en lo inmediato imponía la necesidad de alcanzar una mayor deflación en términos reales como única alternativa duradera para no salirse del esquema convertible. A los ojos de Cancillería esto se tornaba políticamente inviable por el creciente descontento social que imposibilitaba aplicar aquellas medidas. El Presidente De la Rúa rápidamente asumió la posición de Giavarini. Durante los primeros días de febrero, Argentina dio a conocer su posicionamiento junto a Brasil y notificó su posición al Secretario de Estado de los Estados Unidos, Collin Powell. La crisis económica fue decisiva y el pivoteo se mostró impracticable.

Sin embargo, el Ministerio de Economía no abandonó su posición sino que, apremiado por la escasez de divisas, la exacerbó durante los siguientes meses. No obstante, conviene señalar que Giavarini no ponía en discusión la apertura indiscriminada y unilateral realizada durante la primera etapa de las reformas estructurales sino que ponía de manifiesto la intención de contener los efectos de esa apertura. Pretendía hacerlo sin abandonar la Convertibilidad, ni la inserción sin mediaciones en el mercado mundial implícita en ella. Él manifestaba la inviabilidad política del ALCA propuesto por Estados Unidos debido a las crecientes protestas sociales. En ese contexto, apoyarse en Brasil y negociar conjuntamente parecía el modo viable de sortear las consecuencias políticas de la inserción internacional neoliberal y, a la vez, persistir en ella.

Desde nuestro punto de vista, esta posición apuntaba a flexibilizar los mecanismos de subordinación de los trabajadores condensados en la Convertibilidad, aunque de modo contradictorio: negociar el ALCA pero sin realizar una apertura unilateral. Estas controversias y vaivenes no provenían de la falta de firmeza en la política exterior argentina de De la Rúa o de la ausencia de coincidencias entre retórica y práctica, como se difundía en la opinión pública, sino del seno de la crisis de la Convertibilidad y de las alternativas que se abrían para comandarla.

Como vimos en el apartado anterior, al aplicar las reformas neoliberales Brasil había asumido cierto grado de exogeneización de su política como un dato de la realidad, al tiempo que elaboró políticas para limitarla y garantizar sus propios objetivos. La devaluación y modificaciones del Plan Real supusieron un relegamiento de aquella exogeneización. En ese marco fue que se produjeron las negociaciones aquí descriptas entre la Cancillería de Argentina y la de Brasil. De este modo sostenemos que la posición de Giavarini (coludir con Brasil) suponía una incipiente politización de la política exterior y de la inserción de la Argentina en el mercado mundial, relajando los mecanismos de subordinación de los trabajadores condensados en el Plan de Convertibilidad, al tiempo que permitiría conseguir las divisas para su continuidad (pragmatismo comercialista). En espejo la orien- 
tación planteada por Economía suponía sostener los mecanismos despolitizantes y exogeneizantes de la Convertibilidad.

Las tensiones entre ambas carteras se mantuvieron latentes entre julio del 2000 y marzo de 2001. A partir de ese momento, cuando la crisis de la Convertibilidad entró en la recta el final esas tensiones se mostraron como irresolubles y tomaron forma de enfrentamiento abierto.

\section{Contraposición abierta entre Cancillería y Economía: marzo a mayo de 2001}

Como mencionamos anteriormente, la Convertibilidad requería de crecientes aumentos de productividad para que los capitales puedan participar exitosamente en el mercado mundial. Cuando el flujo de divisas no acompañaba las necesidades de la acumulación dentro del esquema convertible, los capitalistas sólo podían formar parte del ciclo del capital global intensificando el trabajo y/o bajando los salarios en términos reales (deflación real). La Convertibilidad, en efecto, suponía un resultado desfavorable para los trabajadores en el conflicto distributivo entre las clases y fracciones de clase. En caso de no mediar el ajuste (nuevas derrotas de los trabajadores), la inserción internacional se tornaba inviable. En este marco, podemos comprender el drástico plan de ajuste que anunció López Murphy en Cadena Nacional a once días de haber asumido.

Los recortes del gasto para 2001, estaban proyectados en 1.962 millones de pesos (dólares) y 2.485 para el año siguiente. Los ajustes deflacionarios atentaban contra la ya golpeada legitimidad del gobierno de la Alianza y generaban más descontento social (Piva, 2012). Con ese trasfondo renunciaron varios ministros, todos del FREPASO. Pocas horas antes de asumir a su cargo como secretario de Hacienda, Daniel Artana declaraba que:

El segundo punto del largo plazo, tiene que ver con las relaciones comerciales de la Argentina. Estamos perdiendo el tren. Ahora, ¿cómo asociarnos con el ALCA y la Unión Europea cuando uno tiene una palabra con el Mercosur? Ahí hay una situación compleja, pero también hay que tener en cuenta una cuestión de sentido práctico en la discusión en el ALCA: si nosotros vamos a discutir juntamente con Brasil, la pregunta es qué se va a terminar cediendo en la discusión bilateral. Por ejemplo, ¿los intereses del complejo agroindustrial y agrícola de la Argentina para favorecer a los intereses de los industriales de San Pablo? ¿Qué es más relevante para los americanos, si estamos discutiendo todos juntos? ¿La economía de Brasil o la argentina? Cuidado que pensar que ir junto a Brasil no tiene costos para la Argentina. También hay un costo por romper la palabra, es una discusión compleja. Lo fundamental es que debemos tener libre comercio con los que tienen comercio en gran escala ${ }^{18}$.

Ya como secretario de Hacienda, Daniel Artana, caracterizaba que para revertir la crisis y revitalizar la Convertibilidad era necesario acomodarse a sus reglas y hacer un ajuste. El Secretario se expresaba sin eufemismos: "[L]os programas con viabilidad políti-

${ }^{18}$ La Nación, 04/03/01. 
ca mantienen hace tres años la economía en recesión" (Citado en Piva, 2012, p. 372). En este sentido, el apoyo de Artana al ALCA enviaba un doble mensaje que servía a los intereses de Economía: por un lado, al igual que Machinea, el nuevo equipo económico consideraba necesario dar señales claras de apoyo al proyecto que Estados Unidos consideraba crucial, con el fin de obtener un trato recíproco frente a los organismos financieros internacionales a la hora de las urgencias financieras. La posición de Artana ante la crisis apuntaba a profundizar la liberalización y la Convertibilidad (Brenta, 2002). Desde su punto de vista, el ALCA era central y no debía medírselo por su viabilidad política sino por representar una garantía para reproducir la Convertibilidad. Pero además, liberalizar el comercio con Estados Unidos era la consecuencia que se desprendía del modo de inserción internacional que imponía el esquema convertible. En este sentido, podemos comprender que la posición del secretario de Hacienda explicitaba al ALCA como parte integrante del funcionamiento de la Convertibilidad y ponía de manifiesto que el núcleo del Tratado compartía los mecanismos de subordinación del trabajo de la forma de Estado neoliberal (Pascual, 2016).

Días después, Artana descalificó al MERCOSUR y encomendó iniciar negociaciones directas con Estados Unidos ${ }^{19}$. De esta manera, desde el ministerio de Economía se planteó una relación simbiótica entre (a) los ajustes para sostener la Convertibilidad y (b) la inserción en el ALCA que hacía a un lado las posiciones comunes con Brasil. Sin embargo, a diferencia de la gestión de Machinea, no se trataba sólo de un pragmatismo urgido de las necesidades de crédito externo sino también de completar la inserción sin mediaciones al mercado mundial.

Sin embargo, la aplicación de un programa económico que atendiera los requerimientos técnicos de la Convertibilidad y las presiones externas independientemente de la viabilidad política, es decir, independientemente de la legitimidad social, se enfrentó con la resistencia social que finalmente imposibilitó la aplicación de los ajustes. El intento de López Murphy de llevar a cabo los recortes suscitó uno de los puntos más álgidos de la resistencia social y representó el principio del fin de la Convertibilidad (Bonnet, 2008). Las manifestaciones en las calles como resultado de los anuncios de López Murphy parecían darle la razón a Giavarini.

Con las calles colmadas de protestas, el gobierno nacional inició negociaciones con el Partido Justicialista y Acción para la República, liderada por Domingo Felipe Cavallo. El 19 de marzo López Murphy renunció a su cargo y fue reemplazado por el ex ministro de Menem. Con su asunción, los recortes anunciados quedaron sin efecto. El regreso de Cavallo al Ministerio de Economía revitalizó el consenso en torno a la Convertibilidad y sus mecanismos de subordinación de los trabajadores. Esto último quedó evidenciado en que en general ninguna protesta apuntó contra el plan económico, incluso en los sectores más radicalizados que rechazaban el ajuste y lo vinculaban con el ALCA.

El arribo de Cavallo, pareció recrear las condiciones políticas en las que los mecanismos despolitizados y exogeneizados se habían constituido con la Convertibilidad. Su figura volvió a situar al Ministerio de Economía como el más importante dentro del Poder

\footnotetext{
${ }^{19}$ La Nación 13/03/01.
} 
Ejecutivo $^{20}$. Pero tras el consenso que generaba Cavallo subyacían fundamentos contradictorios: por un lado, era producto del apoyo de los aspectos positivos de la Convertibilidad (i.e. la estabilidad garantizada por la sujeción al mercado mundial); por el otro, su llegada era consecuencia de la debilidad de los ministros que lo antecedieron para revertir o aplacar el rechazo a los ajustes necesarios para sostener la paridad cambiaria. Esta contradicción, que estallaría meses más tarde, se anticipó en el rechazo que produjo el ALCA. Consideramos que por medio de la resistencia al Tratado puede observarse el rechazo a una cuestión central de las reformas estructurales y la Convertibilidad: la inserción sin mediaciones en el mercado mundial y, a través suyo, a los mecanismos exogeneizados de subordinación del trabajo al capital.

Como parte de su plan de salida de la crisis sin nuevos ajustes, Cavallo presentó medidas de fomento a la producción anticíclicas de carácter heterodoxo (Kan, 2015) ${ }^{21}$. Al mismo tiempo, aceleró la orientación pro-ALCA en perjuicio del MERCOSUR con el objetivo de obtener nuevos créditos por medio de la ayuda norteamericana. Sin embargo, la estrategia de Cavallo no fue viable. Las negociaciones directas con Estados Unidos respecto del ALCA fueron bloqueadas desde dentro del gobierno. La misma resistencia que se produjo contra los ajustes de López Murphy reapareció frente al posicionamiento de Cavallo respecto del ALCA. Pero para regresar al gobierno, Cavallo había puesto como condición el otorgamiento de poderes especiales, incluyendo una mayor injerencia sobre la política exterior. La experiencia de los ministros anteriores indicaba a Cavallo que el Canciller iba a ser un escollo en su estrategia de usar al ALCA como moneda de cambio para acceder a créditos internacionales.

En abril, se realizó una cumbre empresarial y una ministerial del ALCA en Buenos Aires, separadas sólo por unas horas. En ambas se debatió el Tratado. Entre ellas hubo diálogos y afinidad en las posiciones ${ }^{22}$. De la Rúa cerró la cumbre empresarial haciendo pública su posición de negociar el ALCA desde el MERCOSUR. En esos mismos días, en San Pablo, Cavallo dejó trascender su posición, que contradecía al Presidente argentino. Estos dichos se sumaban a las medidas proteccionistas contra algunos productos provenientes de Brasil. Desde ese momento se inició una escalada de confrontaciones verbales entre el Ministro de Economía y funcionarios de Brasil que tensaron las relaciones bilaterales. Cavallo sostenía que Argentina mantenía una "Brasil-dependencia" y acusaba al gigante del MERCOUSR de "imperialista" ${ }^{23}$, lo que realimentó las tensiones entre el Ministro de Economía y el Canciller ${ }^{24}$. Pocos días después de haber trascendido las declara-

\footnotetext{
${ }^{20}$ Tanto fue así que, en medio de las negociaciones por el ALCA y en un clima de extrema tensión entre los países del MERCOSUR, el Presidente Fernando Henrique Cardoso preguntaba públicamente quién mandaba en Argentina (Clarín, 22/04/01)

${ }^{21}$ Los planes de Competitividad involucraban, además de una serie de subsidios para los exportadores, una ampliación de la Convertibilidad empalmada con el euro, mientras la UIA pedía que en la canasta de monedas se incluyera al real, ya devaluado.

${ }^{22}$ La Nación, 07/04/01

${ }^{23}$ La Nación, 08/04/01, 24/04/01

${ }^{24}$ En medio del debate, el periodista Joaquín Morales Solá mostraba la necesidad de alineamiento entre los ministerios y de la Argentina con Estados Unidos. Exhortaba a la unidad de criterios entre los ministros y recordaba la sintonía que había habido entre Cavallo y el ex Canciller Guido Di Tella durante el gobierno de Menem. "Guido Di Tella (quien no merecía, al igual que Oscar Camilión, terminar su carrera política entre jueces y dando explicaciones por negocios sucios que ninguno de los dos hizo) fue el canciller que
} 
ciones de Cavallo, el Presidente Cardoso posponía un encuentro que iba a tener con su par argentino en ocasión de la previa a las negociaciones del ALCA en Quebec.

Ya en la cumbre de Quebec, el Presidente Cardoso expuso -frente a las presiones norteamericanas- que la adhesión de Brasil al ALCA dependía de la resolución favorable de algunos tópicos controversiales, como el uso de medidas antidumping y subsidios, que impiden las exportaciones de acero, soja y jugo de naranja a Estados Unidos (Hakim, 2002 , p. 153). Estas posiciones, por parte de quien promovió la liberalización comercial de Brasil, se relacionaban con las transformaciones en los equilibrios de poder entre las clases y sus fracciones que emergieron desde la crisis cambiaria de 1999 , a la que hemos hecho referencia ${ }^{25}$.

Bajo ese clima de tensiones con Brasil, y en medio de la crisis de la Convertibilidad, De la Rúa mantuvo una reunión con el primer mandatario norteamericano. El Presidente Bush (h) expresó su apoyo a Argentina y declaró que su gobierno le ofrecería sostén político y económico cuando fuera necesario ${ }^{26}$. Como gesto de apoyo político, Bush (h) declaró que Argentina tenía la suerte de afrontar la crisis bajo el "liderazgo fuerte" ${ }^{27}$ de Fernando De la Rúa. De todos modos, el Presidente argentino había acordado con Cavallo que Argentina no iba a pedir dinero en ese encuentro ${ }^{28}$.

Desde San Pablo y luego desde Inglaterra, el Ministro de Economía de Argentina declaró su preferencia por iniciar negociaciones bilaterales con Estados Unidos y la Unión Europea, y puso en duda que Brasil pudiera superar las presiones internas para avanzar en esos ámbitos ${ }^{29}$. Ante este panorama de posiciones cruzadas entre Cavallo y De la Rúa, el mandatario brasileño exhortó a que Argentina aclarara quién era la voz de mando ${ }^{30}$. EI Presidente Cardoso cargó contra su par argentino cuestionando la supuesta firmeza de De la Rúa halagada por Bush (h). La caída de Bolsa de Comercio y el aumento del riesgo país reflejaron esta incertidumbre ${ }^{31}$ y exponían la debilidad de Cavallo para imponer su

mejor expresó a Cavallo. Di Tella solía decir que si el destino de la Argentina era andar a la zaga de un gigante, entonces era preferible que fuera detrás del gigante más grande" La Nación, 08/04/01.

${ }^{25}$ Por un lado, la burguesía mercadointernista vinculada a la producción de electrónica, bienes de capital, papel y celulosa -entre otros sectores-, rechazaban el ALCA. En cambio, "los apoyos a la propuesta provenían de sectores como el agrobusiness, el acero, el calzado y los textiles, cuya producción se orientaba al exterior; estos sectores fueron los menos perjudicados por la apertura de los '90" (Boito y Berringer, 2014: 103). La FIESP estimaba una merma en las exportaciones de mil millones de dólares anuales de concretarse el ALCA (Rapoport y Lamadrid, 2011: 75). Por otra parte, desde diversos sectores de la sociedad civil, la CUT, el MST, la Confederación Nacional de Obispos de Brasil, Consulta Popular, el PT y otros agrupamientos construyeran una campaña nacional contra el ALCA y el neoliberalismo, las cuales fueron facilitadas por la emergencia del Foro Social Mundial realizado en enero de 2001 en Porto Alegre.

${ }^{26}$ Clarín, 23/04/01.

${ }^{27}$ Clarín, 22/04/01.

${ }^{28}$ Página/12, 20/04/01.

${ }^{29}$ Página/12, 20/04/01.

${ }^{30}$ Clarín, 22/04/01.

31 "Las buenas intenciones del principal gobierno del mundo no parecen suficientes para aquietar la incertidumbre argentina. La última caída de la Bolsa y suba del riesgo país (estas cifras preocupan más que ninguna otra cosa al delarruismo) sucedieron al apoyo que Bush (h) ofreció a De la Rúa el jueves, en la Casa Blanca, cuando se reunieron a solas.

Bush (h) manifestó su apoyo dos veces en cuatro días al gobierno argentino; las dos veces, los mercados 
estrategia al conjunto del Ejecutivo. Su principal carta de presentación, el aval de los sectores financieros, le daba la espalda. Esa reacción podría leerse de diferentes formas: a) como respuesta ante la incertidumbre generada por el doble comando; b) como manifestación de las tensiones entre ambas carteras, que cuestionaban la capacidad real del Ministro de Economía para impulsar el crecimiento económico; c) como expresión de las inconsistencias en la política exterior. En sendas interpretaciones subyace un mismo denominador común: la resistencia social que impedía los ajustes.

En este sentido, la propuesta de Cavallo de ir hacia el ALCA para obtener nuevos créditos resultaba contraproducente. Más aún, ponía en evidencia la intensidad de la crisis económica bajo la forma de desacuerdos al interior del Ejecutivo. En efecto, la propuesta de Cavallo carecía de apoyo no sólo al interior del gobierno sino también entre los trabajadores, movimientos desocupados y parte de los empresarios y del establishment (Tussie y Botto, 2003).

En los primeros días del mes de mayo se iba a producir un cruce de posiciones entre el Ministro de Economía y el Canciller que llegaría a niveles inauditos. Previo a una visita de Cavallo y Giavarini a los Estados Unidos, los ministros habían acordado sostener la posición del Canciller respecto del ALCA: negociar desde el MERCOSUR junto a Brasil. Pero el ministro Cavallo rompió el acuerdo. En ocasión de solicitar que bajaran la tasa de interés, volvió a presentar su postura a favor de iniciar negociaciones bilaterales con Estados Unidos. En ese mismo sentido, el 5 de mayo, en una conferencia que el Ministro de Economía dio en la Universidad de Harvard, expresó la inutilidad del MERCOSUR para la Argentina. Simultáneamente, Giavarini dejaba trascender que las relaciones con el creador del esquema convertible eran buenas, aunque también expresaba las discrepancias que tenían respecto del MERCOSUR y el ALCA. Además, ratificaba que Argentina negociaría el ALCA desde el MERCOSUR y que esa era la posición del Presidente ${ }^{32}$. Todo esto añadió mayor incertidumbre no sólo sobre la política exterior sino también sobre la capacidad que tendría Cavallo para desarrollar su plan para sostener la Convertibilidad.

Días después, en la visita conjunta que hicieron a Washington, Cavallo volvió a insistir con que Argentina debía iniciar negociaciones bilaterales con Estados Unidos al margen del MERCOSUR. Estas declaraciones de Cavallo se producían en simultáneo a las del Canciller que desautorizaron al ministro de Economía y, con él, su estrategia de dar apoyo al ALCA a cambio de nuevos créditos $^{33}$.

Al regresar a Buenos Aires, Cavallo desmintió aquellos dichos y declaró que el ALCA iba a ser negociado desde un esquema de cuatro más uno (Brasil, Argentina, Uruguay y Paraguay con Estados Unidos). Sus declaraciones eludían cualquier mención sobre el MERCOSUR, lo que evidenció, una vez más, su postura de evitar acoplarse a la posición

reaccionaron con más desconfianza hacia la Argentina. "El apoyo de Bush no sirvió para nada", lamentó un integrante del entorno presidencial". La Nación, 23/04/01.

${ }^{32}$ La Nación, 07/05/01, 08/05/01; Clarín, 07/05/01.

33 “<<Mi posición y la del Presidente es muy clara: todo lo demás son estilos personales que podrán servir para mil cosas y para otras no〉>, dijo el canciller, cuando La Nación lo consultó sobre las opiniones de su par de Economía". (La Nación 08/05/01). "[Días atrás] Tras haber criticado nuevamente al Mercosur en la Universidad de Harvard, el ministro de Economía, Domingo Cavallo, fue desautorizado aquí por el canciIler, Adalberto Rodríguez Giavarini. "El Presidente De la Rúa está dispuesto a profundizar el Mercosur. Eso es lo que acordó con su colega de Brasil, Fernando Cardoso. Y en esa tarea estamos", afirmó." Clarín, 07/05/01. 
de Brasil. Por su parte, Giavarini fue terminante respecto de la estrategia de Cavallo: dio a conocer que Argentina había rechazado un ofrecimiento norteamericano de iniciar negociaciones bilaterales. De este modo expuso públicamente que la estrategia de Cavallo no contaba con el apoyo del gobierno, dejándola sin efecto ${ }^{34}$. Sin embargo, el Ministro de Economía no daba tregua: "Yo [Cavallo] ya he dicho que las naciones que estamos en el Mercosur no debemos desaprovechar este plano de posibilidades que nos da la negociación bilateral; por lo tanto, la Argentina va a insistir en el ámbito del Mercosur que además de la negociación del ALCA, avancemos en una negociación bilateral con Estados Unidos" ${ }^{35}$.

Las declaraciones cruzadas confirmaban la crisis. Los créditos no llegaban y el ALCA no podía ser moneda de cambio. Más aún, ni Estados Unidos ni el FMI podían garantizar la continuidad de la Convertibilidad ya que las resistencias sociales habían bloqueado el ajuste requerido, quitándole viabilidad política al programa económico. Con ese bloqueo como trasfondo la crisis política se profundizó. Los siguientes intentos de ajuste fueron resistidos por diversos sectores de la sociedad y por casi todo el establishment político: legisladores de la coalición gobernante y de la oposición; así como por casi todos los gobernadores, independientemente de la fuerza política a la que pertenecieran (Piva, 2012; Bonnet, 2008).

En síntesis, la carta de Cavallo de cambiar ALCA por crédito no sólo quedaba sin efecto sino que además mostraba su incapacidad ante la resistencia social a los ajustes necesarios para acceder a esos créditos ${ }^{36}$. Resistencia que también se manifestó en la imposibilidad de negociar el ALCA sin el MERCOSUR.

No obstante, cabe insistir en que la estrategia de Cavallo de vincular al ALCA con la continuidad de la Convertibilidad no era únicamente pragmática. La inserción sin mediaciones en el mercado mundial que promovía la Convertibilidad conducía a la propuesta del ALCA para eliminar las restricciones regionales al pleno funcionamiento de la ley del valor. Un acuerdo como el ALCA o un tratado de libre comercio bilateral con Estados Unidos operaría como la reafirmación y extensión regional de la subordinación del trabajo exogeneizada y despolitizada. Sin embargo, las dificultades para implementar tal orientación no provenían del propio Plan de Convertibilidad sino de la resistencia contra los ajustes; es decir, contra los medios necesarios para superar la crisis económica. La confrontación entre el Canciller, el Presidente y Cavallo se erigía sobre la crisis de aquellos

\footnotetext{
34 "Ayer, el canciller Adalberto Rodríguez Giavarini y el subsecretario de Estado para Asuntos Hemisféricos norteamericano, Peter Romero, confirmaron que los Estados Unidos ofreció a la Argentina la posibilidad de negociar un tratado bilateral comercial, si es que el ALCA se demora [...] Si bien el canciller defiende el Mercosur como vía de ingreso al ALCA, Cavallo viene reivindicando la alternativa bilateral para llegar a esa instancia". La Nación 08/05/01.

${ }^{35}$ La Nación 09/05/01

${ }^{36}$ Un editorialista del diario Clarín 22/04/01 (destacado en el original) lo expresaba del siguiente modo:

"El ministro de Economía tiene otra contra. Al establishment local y a los representantes del Fondo Monetario Internacional se les atragantó el abrupto final de Ricardo López Murphy: no tanto él como sus estrictas medidas de ajuste resumieron el pensar de los hombres de finanzas y de empresas. Se rindieron recién cuando entendieron que la convulsión social que se cernía como consecuencia de aquel plan podía terminar desmembrando la institucionalidad de la Argentina. Se mecen desde entonces en una contradicción: admiten a Cavallo como hombre de emergencia, pero añoran el recetario prometido por López Murphy".
} 
mecanismos expresando una creciente deslegitimación del gobierno. Allí se inscribía la posición de Giavarini de coludir con Brasil y por ese medio repolitizar la política exterior.

Dicho de otra manera, la imposibilidad de la estrategia seguida por Cavallo era, en cierto modo, una derrota parcial de los mecanismos de subordinación despolitizados y exogeneizados del trabajo al capital, en tanto que ponían en suspenso la continuidad de las relaciones sociales inscriptas en la Convertibilidad y su profundización a través del ALCA. La resistencia que imposibilitaba los ajustes para continuar con la Convertibilidad se expresaba, pues, como un bloqueo a la estrategia de Cavallo de profundizarla por medio de créditos a cambio de un acuerdo como el ALCA o un tratado de libre comercio bilateral con Estados Unidos. El triunfo de Giavarini sobre Cavallo significaba asumir un tipo de política exterior incipientemente politizada, como la impulsada por Brasil, lo que a su vez entraba en tensión con la forma de Estado despolitizada propia de la Convertibilidad. El vínculo entre las tensiones al interior del gobierno y la crisis de la Convertibilidad -y por tanto de la inserción en el mercado mundial- no es necesario ${ }^{37}$, sino que entre ambas mediaba la inviabilidad política del ajuste.

La estrategia de Cavallo, no halló sustento en casi ningún sector social. En cierto modo, la posición de Giavarini se apoyaba en el rechazo social suscitado por el ALCA y en la posición del establishment político y empresarial, es decir, en la inviabilidad política de negociar el Tratado bilateralmente. La cumbre empresarial y ministerial de abril realizada en Buenos Aires fue crucial ya que las distintas fracciones de la burguesía local se manifestaron en favor de negociar el ALCA junto a Brasil. Las posiciones de una buena parte de la burguesía confirmaban las del Canciller y el Presidente en las negociaciones por el ALCA, incluso cuando estas mismas fracciones se habían declarado en favor de la llegada de Cavallo al ministerio de Economía y habían apoyado sus medidas heterodoxas. Mientras, diversos sectores de la sociedad civil se movilizaron en contra del acuerdo del ALCA manifestando un rechazo frontal al Tratado, aunque una parte de ellos había acordado evitar un paro nacional cuando se anunció el regreso de Cavallo al ministerio. En efecto, durante las reuniones empresariales y gubernamentales (realizadas en Buenos Aires), en el marco de distintas protestas, se movilizaron las dos CGT (Daer y Moyano) y la CTA. La única posición relativamente conciliatoria fue la de la CGT oficial conducida por Rodolfo Daer.

El 6 de abril, se movilizaron por separado la CGT oficial de Daer, la CGT disidente de Moyano y la CTA. Las tres centrales obreras recibieron apoyos de otras centrales sindicales del continente. A la CTA se sumaron un conjunto de organizaciones sociales, civiles y partidos de izquierda, así como altermundistas, estudiantes y sectores de la pequeña burguesía. Cada una efectuó distintas demandas. La CGT oficial reclamó por la inclusión de una cláusula social. La CGT disidente pidió que el gobierno rechazara el ALCA. La CTA expresó su rechazo a las políticas neoliberales y las vinculaba con la globalización neoliberal, ambas cuestiones identificadas e impugnadas junto al ALCA. El resto de la sociedad civil también se expresó contraria al ALCA. Se lo vinculaba con las políticas neoliberales, el ajuste, los Estados Unidos, el FMI y la pérdida de soberanía. La Convertibilidad quedaba fuera de la impugnación, tal vez, por el consenso que aún mantenía. Como sea, la aprobación social al regreso de Cavallo no se traducía en un apoyo a su estrategia de

\footnotetext{
${ }^{37}$ Como ya señalamos, en Brasil en 1999 la devaluación y cambios en el Plan Real no estuvo mediada por una crisis política (Martuscelli, 2015) sino por un nuevo acuerdo entre las fracciones de la clase dominante sobre los modos de subordinar a los trabajadores.
} 
negociar el ALCA bilateralmente. Esto también se expresó en la opinión pública y en sectores del establishment político.

En una encuesta realizada por Gallup, publicada por La Nación el 14 de mayo de 2001, se manifestaba una opinión pública escéptica respecto de la potencialidad de la política exterior para superar la crisis. Los resultados de las encuestas contrastaban con la de la década de los noventa en la que la política exterior era considerada como parte del éxito de las reformas estructurales. Simultáneamente, se mantenía la imagen positiva del MERCOSUR.

Por último, a la política pro-ALCA de Cavallo también se le opuso, como un bloque monolítico, los sectores chachistas (FREPASO) y alfonsinistas (UCR) de la Alianza. A lo largo de los dos años del gobierno de la Alianza, estos sectores se habían mantenido proclives al MERCOSUR. Su posición quedó sintetizada en la asamblea de la Alianza realizada en junio de 2001 en la que acordaron apoyar la posición de Giavarini. Los reunidos en esa ocasión rechazaron de forma generalizada la política seguida por el ministro CavaIlo denunciando que dejaba de lado la plataforma electoral de la Alianza ${ }^{38}$. Finalmente, poco tiempo antes de las elecciones de octubre, la Alianza acordó con el partido justicialista quitar al ALCA de la agenda electoral.

\section{Palabras finales}

En este artículo, mostramos que las posiciones del gobierno nacional durante los años 2000 y 2001 quedaron sujetos al desarrollo de la crisis de la Convertibilidad. Identificamos las tensiones al interior del gobierno como una manifestación de la crisis de los mecanismos de subordinación del trabajo exogeneizados y despolitizados inherentes a la Convertibilidad. En este sentido, la conclusión principal es que la posición de Giavarini de negociar junto a Brasil expresaba de forma condensada y desplazada la crisis de aquellos mecanismos. Justamente, la presencia de análogos mecanismos de subordinación en el ALCA y en la forma de Estado neoliberal (sintetizados en la Convertibilidad) nos lleva hacia esta conclusión. Es decir, la crisis de los mecanismos de subordinación de los trabajadores inscriptos en la Convertibilidad producto de la resistencia a los ajustes deflacionarios, se expresaron en las orientaciones contrapuestas en torno al ALCA. En tal sentido, acompañar la posición de Brasil atendía la inviabilidad política de profundizar la Convertibilidad sin modificaciones. Así, la posición de Giavarini de acompañar la posición de Brasil politizaba la política exterior de Argentina de modo indirecto y ponía en tensión los mecanismos de subordinación de los trabajadores inscripta en las relaciones sociales que

\footnotetext{
${ }^{38}$ En aquella reunión participaron, por el lado de la UCR, Federico Storani y Jesús Rodríguez, además de los economistas Juan Vital Sorrouille y Roberto Frenkel, el académico Roberto Bouzas y los diplomáticos Roberto García Moritán (secretario de Relaciones Políticas para América latina) y Felipe Frydman (director de Negociaciones con el Mercosur), entre otros. Mientras que por el lado del FREPASO estuvieron Carlos Raimundi y Carlos Chacho Álvarez, entre los más destacados. “En el debate se señaló a Cavallo que la Alianza no está dispuesta a abandonar esta política exterior de Estado, dijo a La Nación el diputado Carlos Raimundi [...] Las metas de los máximos referentes de la coalición de gobierno, como Raúl Alfonsín y Carlos Alvarez, apuntan a fortalecer el Mercosur, y sobre todo la relación con Brasil, oscureciendo un poco el deslumbramiento por la edificación del Área de Libre Comercio de las Américas (ALCA)" (La Nación, $19 / 06 / 01)$
} 
sostenía la Convertibilidad. Esa tensión, en efecto, tuvo como fundamento el bloqueo social a los ajustes deflacionarios.

Por último, visto retrospectivamente, los vaivenes a lo largo del 2001 revisten la importancia de permitir comprender el porvenir de las negociaciones del ALCA. Con la caída de la Convertibilidad terminaron de destrabarse las posiciones del gobierno argentino. El ALCA terminó negociándose atendiendo a los contenidos del Tratado y junto a Brasil. La incipiente politización de la política exterior manifestada en el contrapunto entre Cavallo y Giavarini se concretaría con la devaluación del peso y las transformaciones generales de la forma de Estado.

\section{Bibliografía}

-Arceo, E. (2002). ALCA, neoliberalismo y nuevo pacto colonial, Buenos Aires: Secretaría de Relaciones Internacionales de la Central de los Trabajadores Argentinos

-Berringer, T. (2015) A burguesia brasileira e a política externa nos governos FHC e Lula, Brasil: Ed. Appris.

-Bologna, A. (1998) "La inserción argentina en la sociedad internacional”, en CERIR, La Política Exterior Argentina 1994/1997. Rosario: Ediciones CERIR (Centro de Estudios en Relaciones Internacionales de Rosario).

-Busso, A. y Bologna, A. (1994). "La política exterior argentina a partir del Gobierno de Menem: una presentación”, En CERIR, La política exterior del gobierno de Menem. Seguimiento y reflexiones al promediar su mandato. Rosario: Ediciones CERIR.

-Bonnet, A. (2008) La hegemonía menemista. El neoconservadurismo en Argentina, 19892001, Buenos Aires: Prometeo.

-Corigliano, F. (2000a) "La dimensión multilateral de las relaciones entre Argentina y Estados Unidos durante la década de 1990", en Cisneros, A. y Escudé, C. (comp.) Historia general de las relaciones exteriores de la República Argentina, Buenos Aires: Centro de Estudios de Política Exterior (CEPE) y Consejo Argentino para las Relaciones Internacionales (CARI)

-Corigliano, F. (2000b) "La dimensión bilateral de las relaciones entre Argentina y los Estados Unidos durante la década de 1990: El ingreso al paradigma de "relaciones especiales". en Cisneros, A. y Escudé, C. (comp.) Historia general de las relaciones exteriores de la República Argentina, Buenos Aires: Centro de Estudios de Política Exterior (CEPE) y Consejo Argentino para las Relaciones Internacionales (CARI).

-Diniz, E. (2010) "Empresariado industrial, representação de interesses e ação política: trajetória histórica e novas configurações", Politica e sociedade, Vol. 9, Nro. 17.

-Escudé, C. (1995) El realismo de los Estados débiles, Argentina: GEL.

-Estay, J. y Sánchez, G. (2005) "Una revisión general del ALCA y sus implicaciones", en El ALCA y sus peligros para América Latina, Buenos Aires: CLACSO.

-Ghiotto, L. (2013) "Los tratados bilaterales de inversión y la protección a las inversiones: un análisis del caso argentino". En: Kan, J. y Pascual, R. (comp.) Integrados (?). De- 
bates sobre las relaciones internacionales y la integración regional latinoamericana y europea, Buenos Aires: Imago Mundi.

-Ghiotto, L. y Pascual, R. (2008) “El CIADI y las inversiones: acerca de la necesidad de certezas", en Revista Realidad Económica, agosto, nro. 238.

-Grigera, J. (2011) Argentina después de la convertibilidad (2002-2011), Argentina: Imago Mundi.

-Hirsch, J. ([1977] 2017). “Elementos para una teoría materialista del Estado". En Bonnet, A. y Piva, A. (comp.) Estado y capital. El debate alemán sobre la derivación del Estado. Argentina: Ed. Herramienta.

http://herramienta.com.ar/estado-y-capital-el-debate-aleman-sobre-laderivacion-del-estado/estado-y-capital-el-debate-aleman

-Holloway, J. y Picciotto, S. (1994) “Capital, crisis y Estado”, en Holloway, J. Marxismo, Estado y Capital, Ed. Tierra del Fuego, Buenos Aires.

-Kan, J. (2009) Crisis económica, burguesía industrial argentina e integración con Brasil. Una tríada clave en la historia reciente del MERCOSUR, Ponencia presentada en el XIV ENEP (Encontro Nacional de Economia Política) de la Sociedad Brasileira de Economía Politica.

-Kan, J. (2015) La integración desde arriba. Los empresarios argentinos frente al MERCOSUR y el ALCA, Buenos Aires: Ciccus-Imago Mundi.

-Lafer, P. ([2001] 2002) La identidad internacional de Brasil, Argentina: FCE.

-Martuscelli, D. (2015) Crises políticas e capitalismo neoliberal no Brasil, Brasil: Editora CRV.

-Míguez, C. (2012) Los partidos políticos y la política exterior argentina. Buenos Aires: Ariel.

-Miranda, R. (2001) “El cambio externo y las estrategias internacionales de la Argentina”, en Relaciones Internacionales, nro. 21, La Plata: IRI-UNLP.

-Morgenfeld, L. (2006), El ALCA: ¿a quién le interesa? Buenos Aires: Ediciones Cooperativas.

-Pascual, R. (2016) La Argentina y el ALCA: de la adhesión incondicional a la oposición abierta. Un análisis desde la perspectiva del marxismo abierto. Tesis doctoral. Facultad de Ciencias Sociales. Universidad de Buenos Aires. Defendida 11/3/2016. https://www.academia.edu/25870863/LA_ARGENTINA_Y_EL_ALCA

-Pascual, R., Ghiotto, L. y Lecumberri, D. (2007) El libre comercio en lucha: una mirada crítica del ALCA, Buenos Aires; Ediciones CCC.

-Piva, A. (2012) Acumulación y hegemonía en la argentina menemista, Buenos Aires: Biblos.

Poulantzas, N. (1986) Estado, Poder y Socialismo, México: Siglo XXI.

-Robinson, W. (2009) Latin America and global capitalism, Estados Unidos: Johns Hopkin UP.

-Schorr, M. (2001) ¿Atrapados sin salida? La crisis de la convertibilidad y las contradicciones en el bloque de poder económico, Argentina: FLACSO.

-Tussie, D. y Botto, M. (2003). El ALCA y las cumbres de las Américas: ¿una nueva relación público-privada? Buenos Aires: Biblos. 